colectivo popular, en cuyo centro la maravilla y la fascinación, herencia del pasado medieval y renacentista, juegan un papel preponderante.

Un porcentaje importante de las piezas narrativas dedican su breve trama a destacar la intervención de lo ultraterreno, lo milagroso, lo santo, y lo cristiano en la conversión religiosa y la moralización de los indígenas. El sentido didáctico de los cuentos prevalece sobre las diferentes historias, su tratamiento lectivo está dirigido al indígena, eje central de todo esfuerzo doctrinal.

No son los únicos aportes, además de la presentación del libro, en la que se dejan claros el sistema de trabajo y los objetivos de la investigación, la profesora Campos Moreno introduce al lector al análisis de una de las crónicas poco conocida y menos estudiada de la historiografía novohispana. La anexión de un apartado especial para explicar la obra de Antonio Tello constituye un avance notorio en la valoración de los textos coloniales, debido a que tal estudio identifica las fuentes escritas y orales en las que se basó el autor para referir el estado de las cosas en una región clave para entender el trasiego conquistador y colonizador de los europeos en América.

En suma, esta publicación propone una nueva lectura del pasado. Considera a la fuente primaria como un gran contenedor cultural dentro del que permanecen los ecos de las tradiciones occidentales, al tiempo que la polifonía resultante, asumida como identidad y posesión de la verdad, se aplica al entorno inmediato en forma de saber pragmático al servicio de la ideología evangelizadora. La identificación de esas voces y su afán narrativo revela una ansiedad primigenia, impuesta como tarea y propósito de vida en cada crónica doctrinal y de conquista espiritual.

https://doi.org/10.32735/S0718-2201201900049761

Alberto Ortiz

Universidad Autónoma de Zacatecas (México) albor2002@gmail.com

\title{
Tomás MOULIAN. Democracia y socialismo. Santiago: LOM, 2018, 289 pp.
}

Tomás Moulian debe ser considerado como uno de los pilares del pensamiento crítico de la época contemporánea. Reconocido por su potente crítica al "modelo chileno" en su multicitado libro Anatomía de un mito, el conjunto de su obra ha recorrido ya un largo camino que interpela a las ciencias sociales y a las humanidades. No es el momento ni el lugar para exponer detalles biográficos o del itinerario político de un autor que entiende la producción intelectual como intervención en la coyuntura, en coordenadas nada sencillas, que van de la dictadura chilena - una de las más violentas- al modelo de transición más longevo de la región. Todo ello a partir de una matriz proporcionada por una de las derrotas políticas de las izquierdas más estrepitosa a nivel mundial.

Es precisamente este el núcleo interpretativo que se desprende Democracia y socialismo, libro que vuelve a colocar a disposición del lector y lectora un conjunto de escritos redactados entre los años setenta y ochenta, en donde se expresan tanto las 
tensiones de la coyuntura que se cerraba, como el intento de su cabal comprensión en términos de la práctica política y de la lectura teórica de la coyuntura. Los conceptos de democracia y socialismo no deben ser entendidos en la escritura del sociólogo chileno a partir de una limitada comprensión conceptual. Se trata de verdaderas regiones del pensamiento moderno en las que se ha jugado el destino de la sociedad. Ambos conceptos hacen parte de un intento de articulación de la teoría a partir de la política. Esta última era comprendida como el campo abierto para las grandes tendencias que transformaban las relaciones sociales.

Así, democracia y socialismo son regiones amplias en donde lo que se juega es el desarrollo, la democratización, la dirección política, la relación de fuerza (o la debilidad), los proyectos, los sueños, las proyecciones y, por supuesto, también las incapacidades y los límites. Eso queda expresado en el conjunto de los ensayos, redactados en distintos momentos y originados a partir de diversas instancias. Se imponen, sin embargo, dos grandes motivos: la lectura de la coyuntura clausurada y los efectos vigentes acerca del campo de la teoría.

El primero de los aspectos, que reúne gran parte de los ensayos, bajo el epíteto de "Historia", podemos afirmar que Moulian efectivamente es un perspicaz lector de la coyuntura. Así, "Lucha política y clases sociales en el periodo 1970-193", "Evolución histórica de la izquierda chilena: la influencia del marxismo" y "Desajustes y crisis estatal en Chile" conforman ese corpus de aprehensión de la realidad que dio lugar a la derrota del proyecto popular más esperanzador en los años setenta. En tanto que lector de las tendencias de la sociedad en una coyuntura, emprende el laborioso trabajo de armar las principales líneas a partir de las cuales hacer racional un proceso que se muestra atravesado por múltiples contradicciones, dilemas y tensiones. También, sin embargo, apuesta a concentrar un conjunto de determinaciones que resultan fundamentales: el campo de lo nacional-popular, la dirección política y todo aquello que tenga que ver con la relación de fuerzas entre los agentes que disputaban un lugar en el teatro de operación de la lucha política en el Chile de la segunda mitad del siglo XX.

Leer la coyuntura no es fácil, requiere de una maduración intelectual que no siempre llega a buen puerto. La consigna fácil, el apriori metodológico, la sombra de procesos que por su naturaleza no permiten discernir entre matices o periodos, son algunos de los riesgos más comunes. El acceso de los documentos que este libro permite, en los que Moulian expresa él mismo las contradicciones de comprensión de una época, apuntalan a una temprana madurez, en donde el conjunto de proyectos que dieron vida a la Unidad Popular se tejen, de manera dispar, a partir de caracterizaciones históricas disímiles. Por un lado, los partidos y sus respectivas historias, el movimiento popular en sus múltiples manifestaciones, la "lucha de clases" que estalla por aquí y por allá; la dirección política que busca ser guía, síntesis y cabeza racional de procesos contingentes. Del otro, el "enemigo" político, las tendencias conservadoras, los grupos ultras de la derecha, las vacilaciones del centro que busca recuperar su espacio perdido. En medio, la incapacidad de la construcción de lo nacional-popular. 
Es este tema, sin duda, donde Moulian parece aportar más para la actual coyuntura teórica que vivimos en el conjunto de América Latina. En medio de una andanada massmediática en contra del populismo, el aporte del sociólogo permite comprender la especificidad, en el caso chileno, de la perspectiva nacional-popular, tanto en el marco de las relaciones sociales en general, como en las negociaciones programáticas de las estrategias de las izquierdas y su capacidad o incapacidad para formular una dirección política a partir de ese componente.

Lo voluntad nacional-popular es la dimensión que atraviesa al conjunto de la historia de América Latina durante el siglo XX. Deudora de la perspectiva gramsciana-en el terreno de lo teórico- no deja de ser una imposición de la propia reproducción de las relaciones sociales. Por un lado, un capitalismo oligárquico y monopólico y por el otro, un conjunto de iniciativas en pos de eso que Max Weber llamó la "democratización social", en donde lo nacional (y con ello la dimensión estatal) podía ser modificado o determinado a partir del impulso de los sectores populares. La historia de América Latina es, en gran medida, la de los procesos victoriosos o frustrados de dicha perspectiva.

Lo nacional popular, dice Moulian, no es un programa, sino un proyecto que orienta, es decir, que sirve de brújula. Desde su perspectiva, la búsqueda de consensos sobre la base de la democratización es lo que permite señalar que el socialismo está siempre presente en este proyecto. No a la manera de un programa incrustado por la fuerza, sino por el desarrollo natural de lo nacional-popular, que permite en el transcurso de las grandes movilizaciones desarrollar una relación distinta entre socialismo, democracia y libertad. Lo nacional-popular no es un programa de estatización, ni tampoco un consenso ficticio acerca de la representación popular, es el marco de alianzas que permiten ampliar los márgenes de acción, su formulación es el "techo" en el que es posible un programa que incluya la democracia en un sentido tan formal como radical.

Lo nacional-popular procede entonces como una dimensión unificada en el programa, pero desde la diversidad de perspectivas, pues a partir de ella se entiende que la conquista de igualdad política no es sino el resultado de una mayor posibilidad de igualación en lo social. René Zavaleta, el gran teórico de lo nacional-popular, coincidiría plenamente con esta perspectiva, la que recuperó de Weber y su noción de "democratización social": es esta dimensión la que permite entender tanto la tentativa colectiva a lo largo y ancho de América Latina y también la furibunda reacción de las oligarquías. Moulian se consagra, a partir de una experiencia particular, como uno de los principales referentes de lo nacional-popular dentro del ya reducido campo de quienes practican con vitalidad la crítica marxista.

No puede dejar de mencionarse, en la sección "Problemas teóricos", el texto "Cuestiones de teoría política marxista". Varios motivos nos permiten comentar este texto. El primero es que Moulian hizo parte de una amplia - mucho más de lo que hoy podría pensarse- camarada de intelectuales que buscaron en V. I. Lenin un motivo productivo. Desplazando cualquier noción de "leninismo" (en tanto ideología creada y alimentada desde el poder de un Estado) emprendieron la ardua tarea de leer a Lenin y aprender de él. Moulian 
buscó en Lenin algo que Marx no daba u otorgaba de forma insuficiente: una teoría de la política. Sin embargo, en la mejor tradición del pensamiento, el sociólogo analizó la distancia entre el propio revolucionario ruso. Por un lado, desmenuzó en el folleto ¿Quiénes son los amigos del pueblo y cómo luchan contra la socialdemocracia? La tentativa automatista de la historia, el determinismo como explicación teleológica y el reduccionismo como método. Ello para contrastarlo con el ¿Qué hacer? En donde emerge un Lenin de la praxis, que no se encuentra atado a determinismos, ni causalidades fáciles, sino que emplea todos sus recursos para pensar e intervenir en la coyuntura histórica de su momento. En un párrafo que vale la pena citarse, escribe "Debemos renunciar a la exégesis, tanto a la de Lenin como a la de Gramsci. Nuestras lecturas deben ser irreverentes, porque no en vano hemos vivido años adorando mitos intelectuales que se desmoronan estrepitosamente" ( $\mathrm{p}$. 246). Sin duda, es este el núcleo del texto, contrastar el "momento determinista" con el "momento politicista", mostrar la ambigüedad del planteamiento de un autor que considera clásica pero también la potencia de superar sus límites. Todo ello, claro, acompañado de consideraciones metodológicas sobre el trabajo de textos (ortodoxias, heterodoxias, revisionismos) y siguiendo la trayectoria intelectual del revolucionario ruso.

Finalmente, vale la pena referirse a dos aspectos más que se encuentran presentes en el texto. El primero refiere a la evaluación intelectual que el autor realiza en la presentación, destacando la impronta "althusseriana" de la coyuntura teórica en la que produjo la mayor parte de los textos. Moulian es una muestra más de que el "althusserianismo" como categoría que engloba a posiciones muy diversas, resulta inoperante. Tampoco la reducción de la obra de Althusser a un "estructuralismo" ramplón y maniqueo. Por el contrario, la obra del francés actuó como catalizador de un conjunto de posibilidades productivas en el discurso. La segunda, es la brillante exposición hecha en el "prólogo" por el joven intelectual Oscar Ariel Cabezas, quien coloca a Moulian en el lugar que merece.

Finalmente, no deja de ser importante señalar que Moulian pertenece a una generación que pensó la coyuntura en la medida en que se preparó para la intervención en ella. Es decir, su proceso no es ajeno a otras experiencias y hace parte de un caudal más amplio, que supera los estrechos límites tanto del muy común marxismo militante acartonado, así como del erudito pero estéril políticamente marxismo de cátedra. Desde México, donde realizamos la lectura de Democracia y socialismo, no podemos dejar de reconocer la potencia del discurso del sociólogo chileno y celebrar la vuelta en circulación de estos textos.

https://doi.org/10.32735/S0718-2201201900049762

Jaime Ortega

Universidad Autónoma Metropolitana-Xochimilco (México)

jortega@correo.xoc.uam.mx 